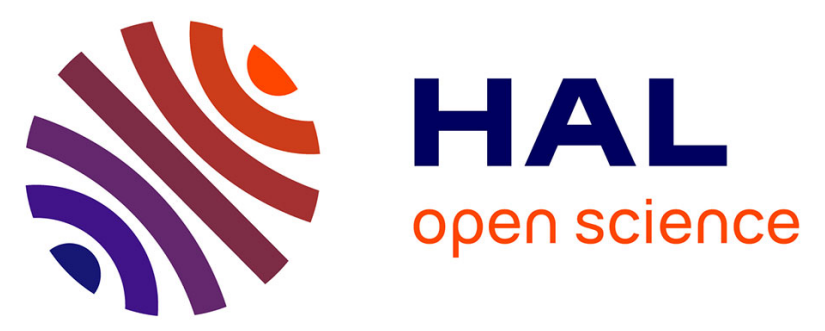

\title{
Characterisation of woven flax fibres reinforcements: Effect of the shear on the in-plane permeability
}

Pierre-Jacques Liotier, Quentin Govignon, Elinor Swery, Sylvain Drapier, Simon Bickerton

\section{- To cite this version:}

Pierre-Jacques Liotier, Quentin Govignon, Elinor Swery, Sylvain Drapier, Simon Bickerton. Characterisation of woven flax fibres reinforcements: Effect of the shear on the in-plane permeability. Journal of Composite Materials, 2015, 49 (27), pp.3415-3430. 10.1177/0021998314565411 . emse-01352778

\section{HAL Id: emse-01352778}

\section{https://hal-emse.ccsd.cnrs.fr/emse-01352778}

Submitted on 6 Nov 2019

HAL is a multi-disciplinary open access archive for the deposit and dissemination of scientific research documents, whether they are published or not. The documents may come from teaching and research institutions in France or abroad, or from public or private research centers.
L'archive ouverte pluridisciplinaire HAL, est destinée au dépôt et à la diffusion de documents scientifiques de niveau recherche, publiés ou non, émanant des établissements d'enseignement et de recherche français ou étrangers, des laboratoires publics ou privés. 


\title{
Characterisation of woven flax fibres reinforcements: Effect of the shear on the in-plane permeability
}

\author{
Pierre-Jacques Liotier', Quentin Govignon ${ }^{2,3}$, Elinor Swery ${ }^{2}$, \\ Sylvain Drapier' and Simon Bickerton ${ }^{2}$
}

\begin{abstract}
This paper describes a method to characterise the influence of in-plane shear on the permeability of fibrous preforms used in liquid composite moulding processes. An optical method for measuring the local shear variation of the woven textile is presented and used in conjunction with an in-plane permeability measurement system. Two flax fibre fabrics were tested and compared with a woven glass fibre fabric of similar architecture. The system presented here can be used either as a validation tool for permeability prediction models or to compile semi-empirical permeability models for the use in liquid composite moulding process simulation tools.
\end{abstract}

\section{Keywords}

Permeability, reinforcing fabrics/textiles, liquid composite moulding, directional orientation

\section{Introduction}

One of the main goals of the transport sector in recent years has been the reduction of energy consumption. This has translated to a strong need in reducing the weight of both structural and non-structural parts manufactured for the aeronautic, railroad and automotive industries. For this, manufacturers are now using an ever-increasing amount of composite materials in their products, benefiting from the materials' low weight compared to their mechanical performance.

The use of bio-based resins and reinforcements made out of natural fibres is currently studied in order to increase the sustainability of the end products. By replacing the traditional synthetic materials that are more commonly used with these, a reduction in the amount of fossil carbon in the structural composites is achieved while the mechanical performances are maintained. The ability to use direct processes, such as liquid composite moulding (LCM) processes, to manufacture large and complex-shaped parts is also maintained, although using such materials tends to exacerbate problems normally encountered during the manufacturing. In addition to this, bio-based reinforcements exhibit a large dispersion in material properties, which is a concern that is currently explored.
Issues relating to interfaces between resins and fibres, as well as resin flow in the fibrous preform, have been previously addressed through the use of specific chemical formulations of the resin or chemical fibres sizing. These solutions, however, detract from the fundamental advantages of using bio-based composite materials.

Standard roving and textile methods applied to flax fibres enable the production of preforms that are suitable for manufacturing bio-based composite parts by LCM processes. The properties of these bio-based reinforcements are a priori different from those of similar non-bio-based reinforcements that were specifically developed for composite processing. Further complexities are also introduced by the applied fabric deformations required to produce complex-shaped composite

'MPE, Laboratoire George Friedel UMR CNRS 5307, ENSM-SE, Saint-Etienne, France

${ }^{2}$ Centre for Advanced Composite Materials, Department of Mechanical Engineering, University of Auckland, Auckland, New Zealand ${ }^{3}$ Université de Toulouse, Mines Albi, INSA, UPS, ISAE, ICA (Institut Clément Ader), Albi, France

\section{Corresponding author:}

Pierre-Jacques Liotier, MPE, Laboratoire George Friedel UMR CNRS 5307, ENSM-SE, I68 Cours Fauriel, Saint-Etienne 42023, France. Email: liotier@emse.fr 
parts. These deformations can have an effect on the impregnation as, for example, in the cases of injection in moulds with double curvature. ${ }^{1-4}$ In addition to this, an effect on the residuals stresses is also observed, ${ }^{5}$ which can induce premature micro-damages in the part but this aspect is the focus of further studies. ${ }^{6-8}$

The present study focuses on the comparison of the in-plane permeability characteristics ${ }^{9-15}$ of two flax fibres reinforcements with different tow sizes as well as a glass fibre reinforcement of an equivalent tow size and architecture (to the first flax reinforcement). In order for the results to be more applicable to the manufacturing of complex-shaped parts, ${ }^{10,16,17}$ the permeability of the fabrics under in-plane shear was of interest. The fabrics have thus been sheared prior to permeability testing in order to simulate preforming in a complex-shaped mould. ${ }^{18-21}$ These deformations affect a number of the manufacturing parameters of interest, such as the compaction and permeability behaviours. ${ }^{9,10,16,17,22-26}$ Effects of several shearing levels measured locally by optical method have been studied at strictly controlled fibre volume fraction.

The main contribution of this study is to couple the permeability measure elements of sheared fabrics with an optical method used to determine the local shear measurement, thereby correlating the actual local shear observed with the preform permeability. The textiles' permeability properties have thus been experimentally characterised, highlighting the effects of shear on the bio-based and glass textiles behaviours at different fibre volume fractions. It is important to note that previous studies have been done at constant thickness, whereas, here, the measurements are made at constant fibre volume fraction.

\section{Materials and methods}

\section{Woven reinforcements}

Three different reinforcements were tested: two flax $2 / 2$ twill weaves (supplied by Libeco) denoted by large and small tow sizes and a glass 2/2 twill weave (supplied by Colan Australia) with a tow width and architecture equivalent to the heavier flax twill weave. The flax twill weave referred to as 'coarse twill' has an areal weight of $550 \mathrm{~g} / \mathrm{m}^{2}$ (grams per square meter). The flax twill weave referred to as 'fine twill' has an areal weight of $315 \mathrm{~g} / \mathrm{m}^{2}$. The equivalent glass twill weave in terms of tow size was chosen with an areal weight of $285 \mathrm{~g} / \mathrm{m}^{2}$. The flax fibres' density has been measured at $1.45 \mathrm{~g} / \mathrm{cm}^{3}$ with a pycnometer. For the glass fibres, the theoretical density for E-glass has been used: $2.58 \mathrm{~g} / \mathrm{cm}^{3}$. Technical information on the different fabrics is provided in Table 1.

Figure 1(a) shows that the coarse twill reinforcement is made of relatively thick and fuzzy tows.

Table I. Technical data of the reinforcements (based on supplier information).

\begin{tabular}{llllllll}
\hline & & & \multicolumn{2}{l}{ Tow count (threads/cm) } & & & \\
Fabric & Areal weight $\left(\mathrm{g} / \mathrm{m}^{2}\right)$ & Tow size $($ Tex $)$ & Warp & Weft & & Weave & Finish \\
\hline Flax fine twill & 315 & 138.9 & 12 & 10 & & Twill 2/2 & Pre-washed \\
Flax coarse twill & 550 & 390 & 7.4 & 7.2 & & Twill 2/2 & Pre-washed \\
Glass & 285 & 204 & 7,1 & 6,5 & & Twill 2/2 & AB7 silane \\
\hline
\end{tabular}
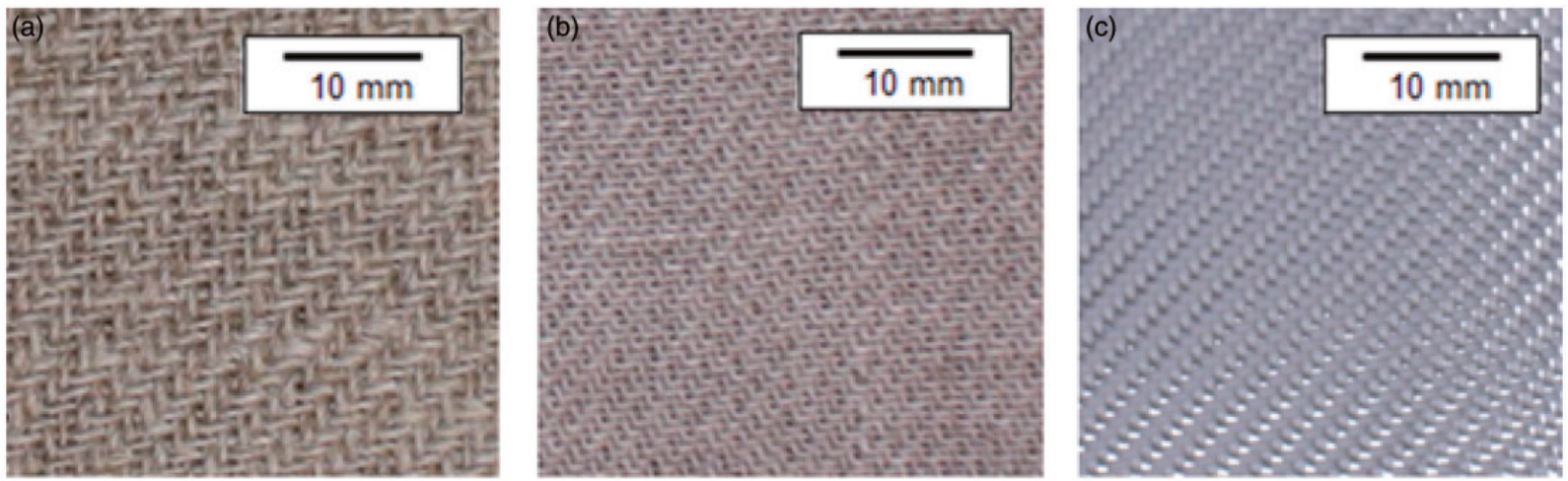

Figure I. Reinforcements used in this study: (a) coarse twill - flax, (b) fine twill - flax, (c) fine twill - glass. 
Figure 2 shows a micrograph of a tow cross section of the fine twill reinforcement presented in Figure 1(b). It can be seen that the tows are made up of several circular pack of twisted fibres. Contrary to this, the glass reinforcement presented in Figure 1(c) has thin, lenticular-shaped tows. The circular section of the individual glass fibres results in a lower friction and thus allows a lower crimp without tows twisting (Figure 3).

\section{Applying shear to the reinforcement Shear rig}

The setup developed in this study is relatively simple yet is the result of several design iterations (Figure 4). It consists of a rig made up of four edges with a clamping mechanism that can be tightened by the use of two bolts on each edge. The nominal shear angle is maintained by two pins on two opposite corners allowing to set the shear angle between $0^{\circ}$ and $45^{\circ}$ with $5^{\circ}$ increments (Figure 4). For each measurement presented in this study, eight layers of fabric have been sheared using this rig.

The sample corners were cut prior to shearing, as illustrated in Figure 5. This prevented out-of-plane wrinkling of the woven fabric which normally occurs in regions of sharp angle changes. ${ }^{27-32}$ This effect was observed to be very strong for the glass reinforcement. To obtain a more uniform shear field, Willems et al. ${ }^{33}$ recommended to maximise the $L_{\text {Frame }} / L_{\text {ROI }}$ ratio, where $L_{\text {ROI }}$ characterises the region of interests as described in Figure 5. For this study, however, this had to be balanced with the need to have a sufficiently large area (large $L_{\mathrm{ROI}}$ ) in order to carry out the permeability experiments. The region of interest is considered as sufficiently distant from the clamped edge, hence any

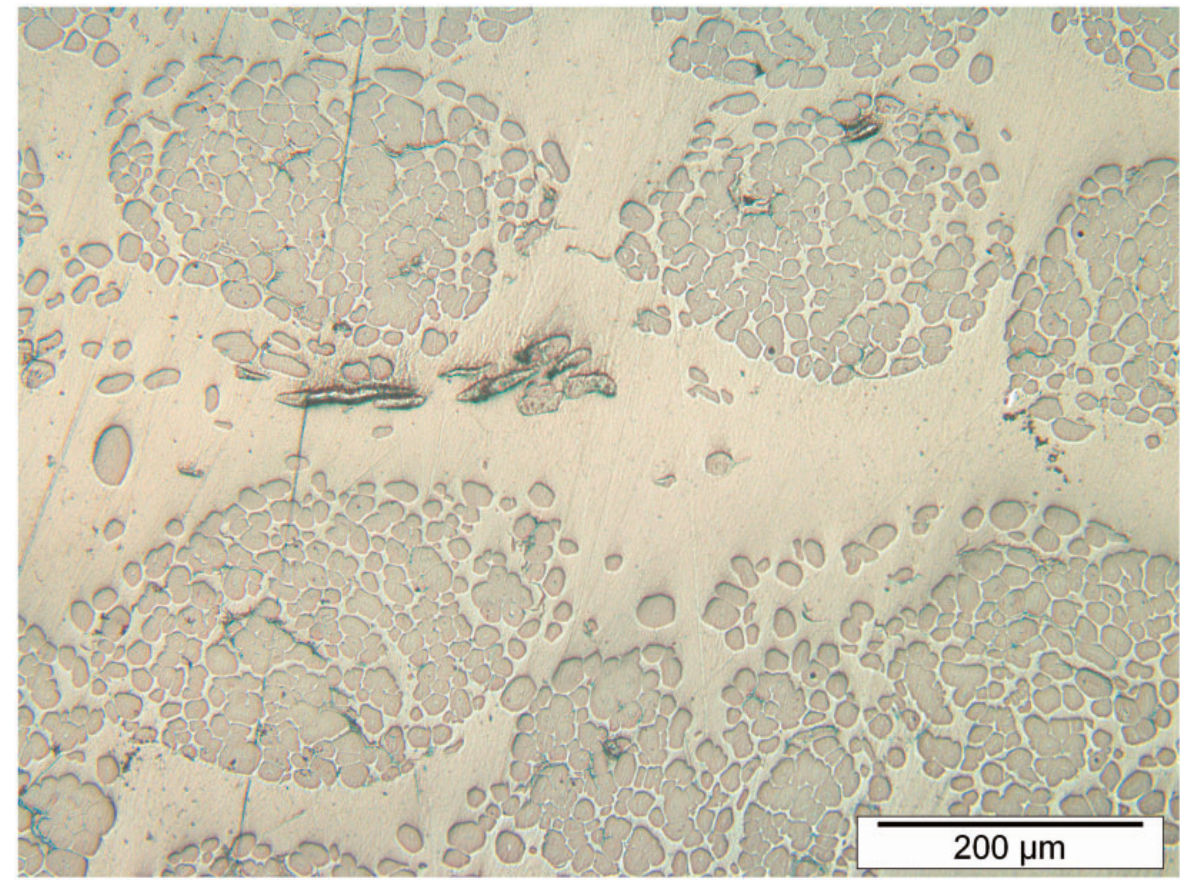

Figure 2. Example of flax tows in epoxy resin.

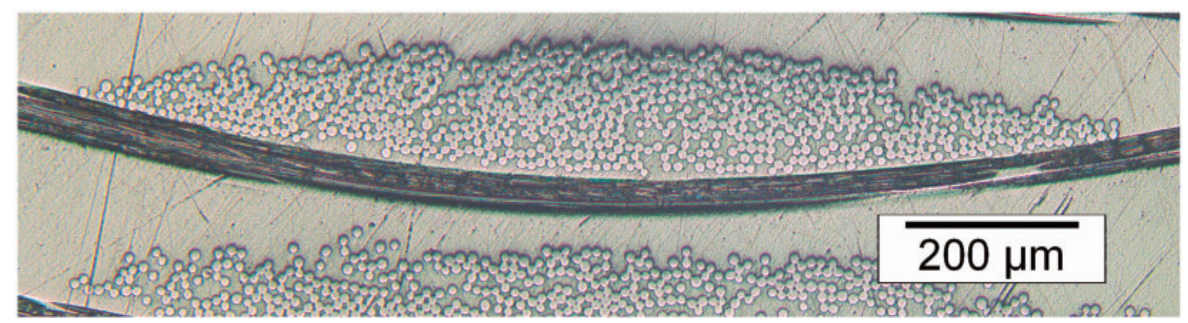

Figure 3. Example of glass tows in epoxy resin. 
tensile forces induced from the permeability experiment are avoided. This area of interest is fixed by the size of the top plate of the permeability setup presented in InPlane Permeability Measurement section. Previous stu$\operatorname{dies}^{9}$ have also recommended removing the loose yarns (yarns that are no longer held by neighbouring yarns), parallel to the frame on the edges of the preform. This was not carried out in this study for practical reason: the tows in the fine twill weave were too small to handle, and there was a need to minimise any additional handling and deformation of the fabrics. As a result, the shearing was observed to be not uniform throughout the entire reinforcement surface in some of the considered cases. ${ }^{33}$ Furthermore, weft and warp misalignments with the rig, which were observed in this study, implied a differences in the fibres tension during the shearing. In order to take into account all of these uncertainties on shearing angles, it was deemed essential to characterise the achieved shear angle of each sample. An optical method was, therefore, developed to measure the local shear angles observed.

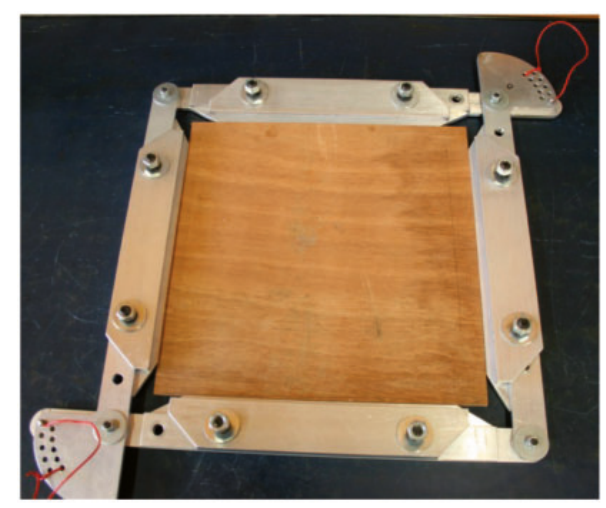

Figure 4. Shear rig.
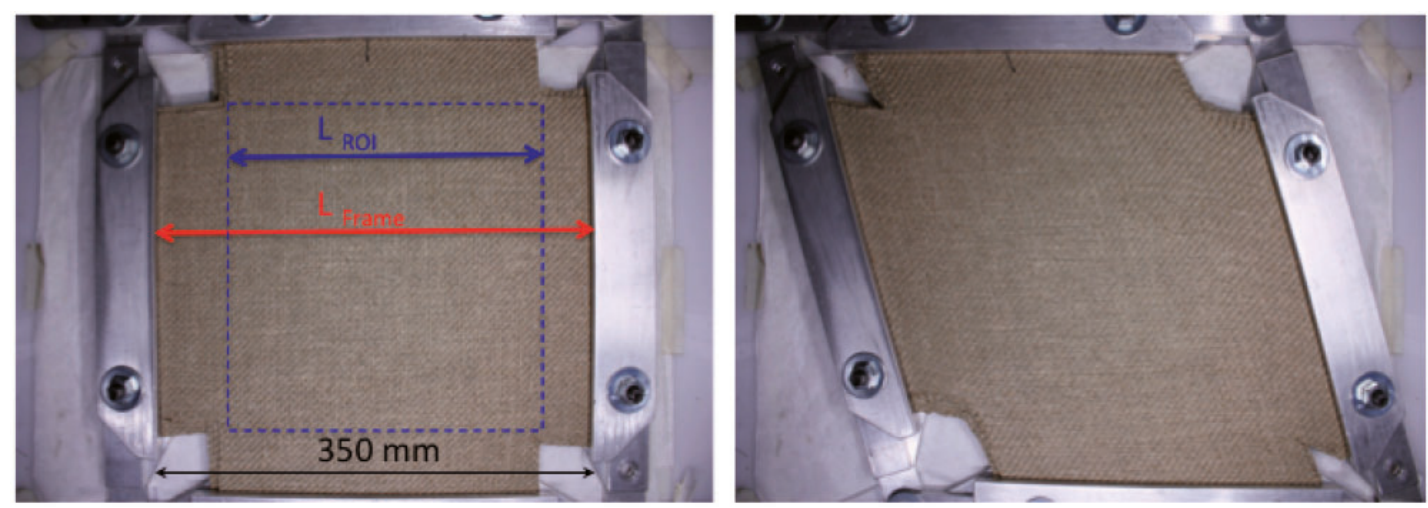

Figure 5. Coarse twill in shear rig initial state (left) and sheared at $15^{\circ}$ (right); $L_{\mathrm{ROI}}=250 \mathrm{~mm}$.
Image analysis techniques for local shear characterisation. While the picture frame rig described above governs the overall shear of the reinforcement, it was deemed necessary to control the actual shear angle imposed on the fabric. ${ }^{11,21}$ Shear variations within the material were present due to shear induced by the cutting and placement of the textile in the rig, as well as sample sliding in the grips as described above. Photographs of the samples were, therefore, taken just before and after deformation in order to evaluate the local variations due to the rig loading. The camera used for taking those photographs was set on a rigid frame and was kept on a rigid frame during all the entire test campaign to ensure a constant distance and angle between the sample and the camera. The pictures were processed using MATLAB ${ }^{\circledR}$, a numerical computing environment. The pictures of the reinforcement were converted to greyscale, cropped to eliminate the picture frame rig, and then divided into square sub-pictures to analyse the spatial dispersion. The pictures were usually defined by $4000 \times 3000$ pixels with a spatial resolution of approximately 0.01 $\mathrm{mm}^{2}$ per pixel to be analysed.

For each sub-picture, represented by the following $M \times N$ matrix (where $M$ is the height of the image and $N$ the width, in pixels):

$$
[A]=\left[\begin{array}{ccc}
a_{11} & \cdots & a_{1 N} \\
\vdots & \ddots & \vdots \\
a_{M 1} & \cdots & a_{M N}
\end{array}\right]
$$

the two-dimensional (2D) Fast Fourier transform (FFT), $Y$, defined as the complex matrix

$$
[Y]=\left[\begin{array}{ccc}
y_{11} & \cdots & y_{1 N} \\
\vdots & \ddots & \vdots \\
y_{M 1} & \cdots & y_{M N}
\end{array}\right]
$$


was computed, where:

$$
Y_{r s}=\sum_{m=1}^{M} \sum_{n=1}^{N} a_{m n} e^{\frac{-2 \pi i(m-1)(r-1)}{M}-\frac{2 \pi i(n-1)(s-1)}{N}}
$$

with $r$ and $s$ the row and column indices of the transformed matrix $[Y] .^{34}$

Using FFT, image data are displayed as frequency patterns that provide information for determining the characteristic angles of the textile structure. ${ }^{35}$ The FFT is used to decompose the input (which, in this case, is a greyscale image), into its sine and cosine components. The output of the transformation represents the input image in the frequency domain and its sinusoidal variations in brightness across the image. The FFT produces a complex number-valued output image which can be displayed with two images; however, here only the magnitude of the transform is displayed, as it contains most of the information of the geometric structure of the spatial domain image. ${ }^{36}$

In order to maintain consistency with the original image, the Fourier transform matrices were rotated by $90^{\circ}$ counter clockwise resulting in the corrected FFT matrix, $\left[Y_{\mathrm{c}}\right]$, defined by equation (3): ${ }^{33}$

$$
\left[Y_{c}\right]\left[\begin{array}{cc}
0 & -1 \\
1 & 0
\end{array}\right][Y]\left[\begin{array}{cc}
0 & 1 \\
-1 & 0
\end{array}\right]
$$

The weft and warp angles were then defined by locating the two angles $(\alpha 1$ and $\alpha 2)$ with the highest intensity $I_{a}$. To calculate this, all angles were tested; the sums of the transform pixel magnitudes along a line at angle $\alpha$ (centred at the image centre) were computed as shown

$$
I_{a}=\sum_{i=1}^{\frac{\min (M, N)}{4}} Y_{c}\left(\left[y_{0}-i \cos a\right],\left[x_{0}-i \sin a\right]\right)
$$

where $\left(x_{0}, y_{0}\right)$ are the centre coordinates of the considered image. An example of this intensity plot is presented in Figure 6.

The angle between weft and warp directions of the fabric can thus be measured independently in different areas of the sheared preform after dividing the initial picture in several sub-windows (Figure 7).

The orientations of each sub-window can then be superimposed onto the original photograph as shown in Figure 8. Here, the central area exhibits a relatively homogeneous shear that is lower than the nominal shear imposed by the rig. The inhomogeneities of the shear angle are predominantly evident in the corners. Corners located in the open angles (upper right and lower left in Figure 9) have not been considered for testing as the local shear is considerably different

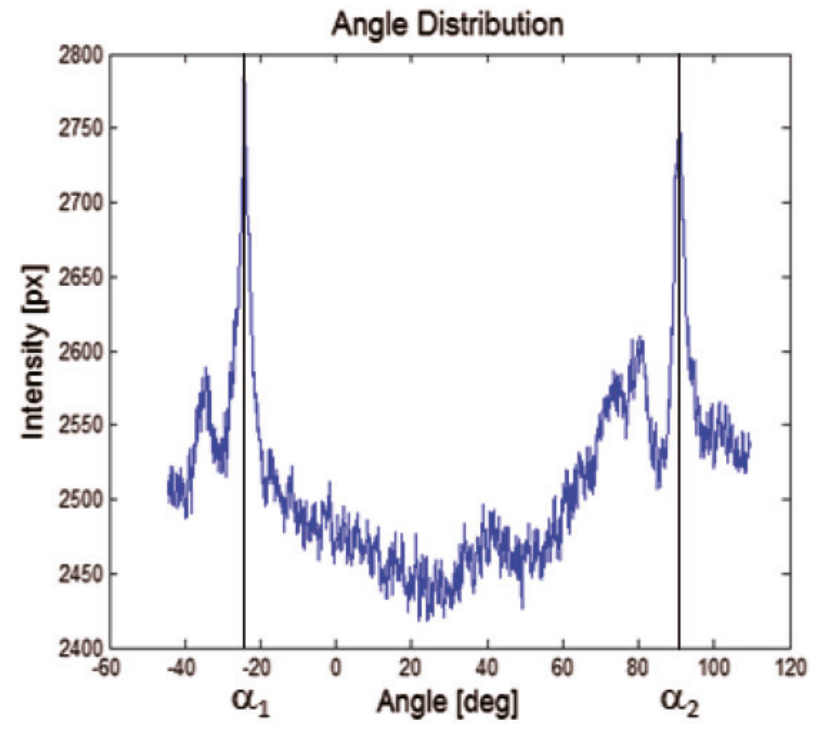

Figure 6. Example of $I_{\alpha}$ plot of sheared twill fabric angles.

from both the nominal shear and the shear measured in the centre of the sample. The shear measurements have been made at the centre of the preform, in the area subjected to resin flow during the permeability tests, thus avoiding the variations at the corners. Those variations, while interesting to note and measure, have thus not been considered in the average shear calculation, and the shear was calculated as the mean value in the area under consideration (i.e. the centred $6 \times 6$ square of sub-windows in Figure 8 ).

Optimisation of the window size. While using a smaller window for subdividing, the original picture will increase the level of detail of the fabric shear distribution, and the FFT calculation requires a certain number of yarns for the repeating pattern to be recognised. Decreasing the size of the analysis window beyond a certain point will, therefore, lead to measurement errors by decreasing the FFT peak size and increasing its spread. With a small analysis window, a twist in the fibre bundle, a detached fibre or a foreign object has been shown to be identified, leading to errors in the measurements. On the contrary, given the variations of shear over the sample area, measurement over a too large window can also lead to a more soften peak due to the spread of fibre orientation. To characterise the spread of the intensity peaks representing the fibre orientations, a Gaussian fit was applied to the intensity plots with an interval of $\pm 8^{\circ}$ around the designated peak. This interval was chosen so as to ensure that the vast majority of the peaks were included. The standard deviation and amplitude of the fitted normal distribution curve can then be used to analyse the accuracy of the measurement. Figure 9 presents the evolution of 


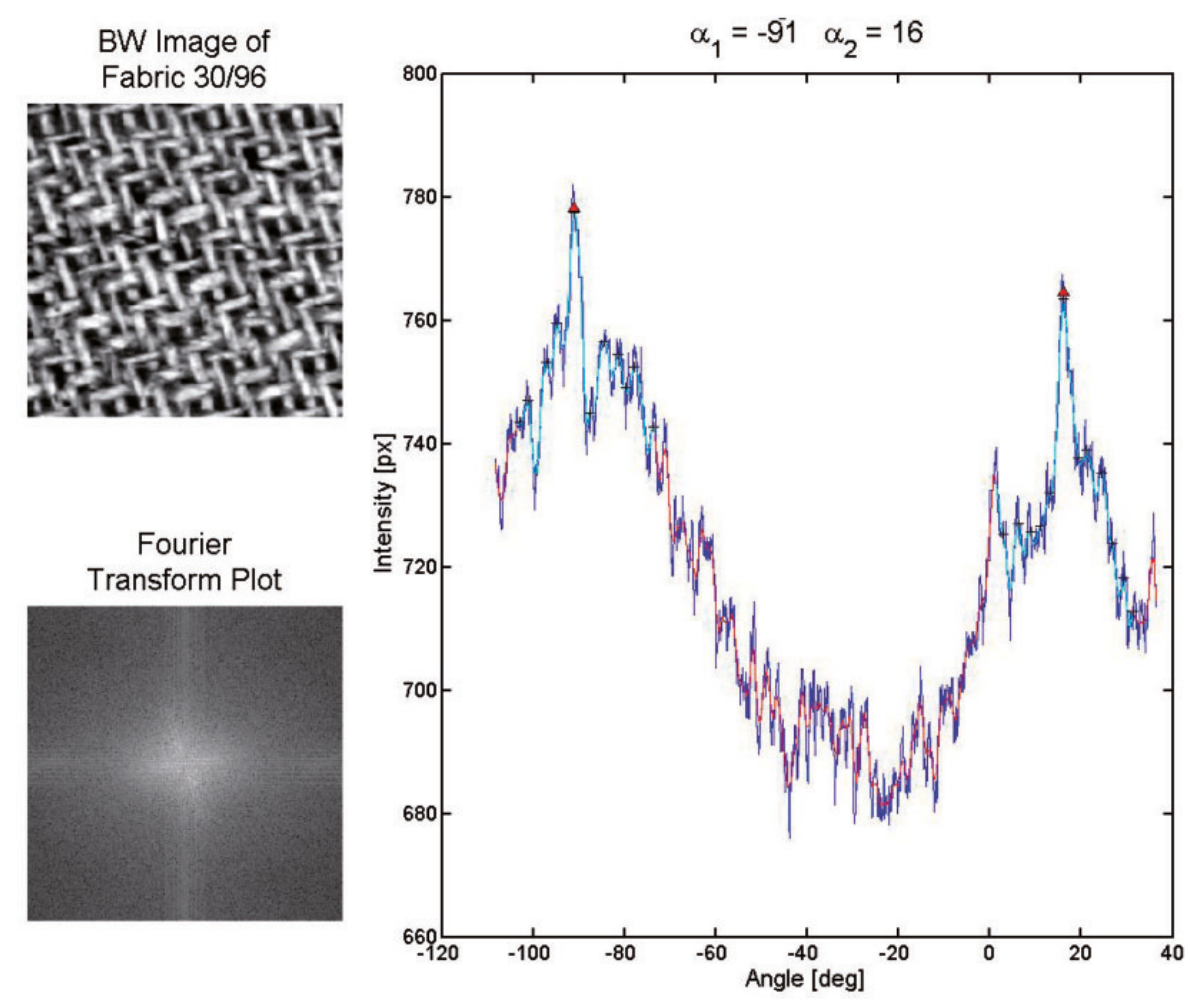

Figure 7. Example of measurement of the local shear on a coarse twill sample with an overall shear of $20^{\circ}$.

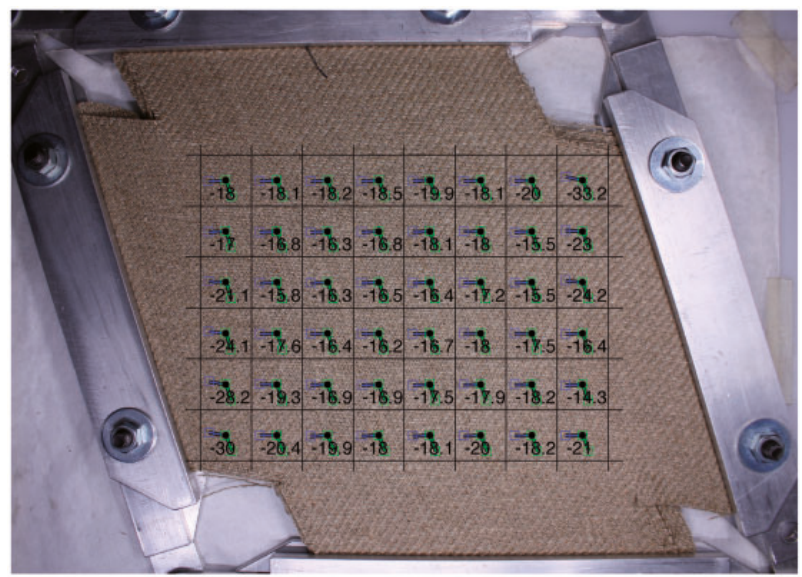

Figure 8. Areal distribution of the local shear on a coarse twill sample with a nominal shear of $20^{\circ}$.

the average standard deviation of the Gaussian fit applied to the intensity traces as a function of the size of the measurement window; a small standard deviation is associated with a sharp peak and therefore a more precise measurement of the fibre orientation. A prominent increase in the measurement error is present when using window size smaller than 200 pixels. This limit was not due to the camera resolution but rather to the decreasing number of repeating unit cells in the weave. On the other hand for larger windows, the increase in repeating unit cells is counterbalanced with the increased spread of orientation especially towards the edges of the preform.

\section{In-plane permeability measurement}

The in-plane permeability facility used was previously developed at the Centre for Advanced Composite Materials (Auckland University, New Zealand) and is depicted in Figure 10. ${ }^{37,38}$ This test facility is installed on an Instron 1186 universal testing machine. The Instron is used to provide accurate control of the parallelism and positioning of the two plates (Figure 10) as well as to enable the measurement of the total compaction force applied. A radial flow injection was used to avoid complications due to race tracking, and the fluid was injected at a constant pressure.

The sample is placed between the upper and lower platens. The upper platen is a $250-\mathrm{mm}$ diameter $\times$ 30 -mm-thick aluminium disc with a 10 -mm diameter hole in the centre for fluid injection. The lower platen, constructed out of glass, allows for optical monitoring of the flow front position and is a $350 \times 56-\mathrm{mm}$-thick square. To ensure proper $2 \mathrm{D}$ flow, a $15-\mathrm{mm}$ diameter hole is punched at the centre of the preform. The fluid flow front is captured using a camera and processed using image analysis techniques 


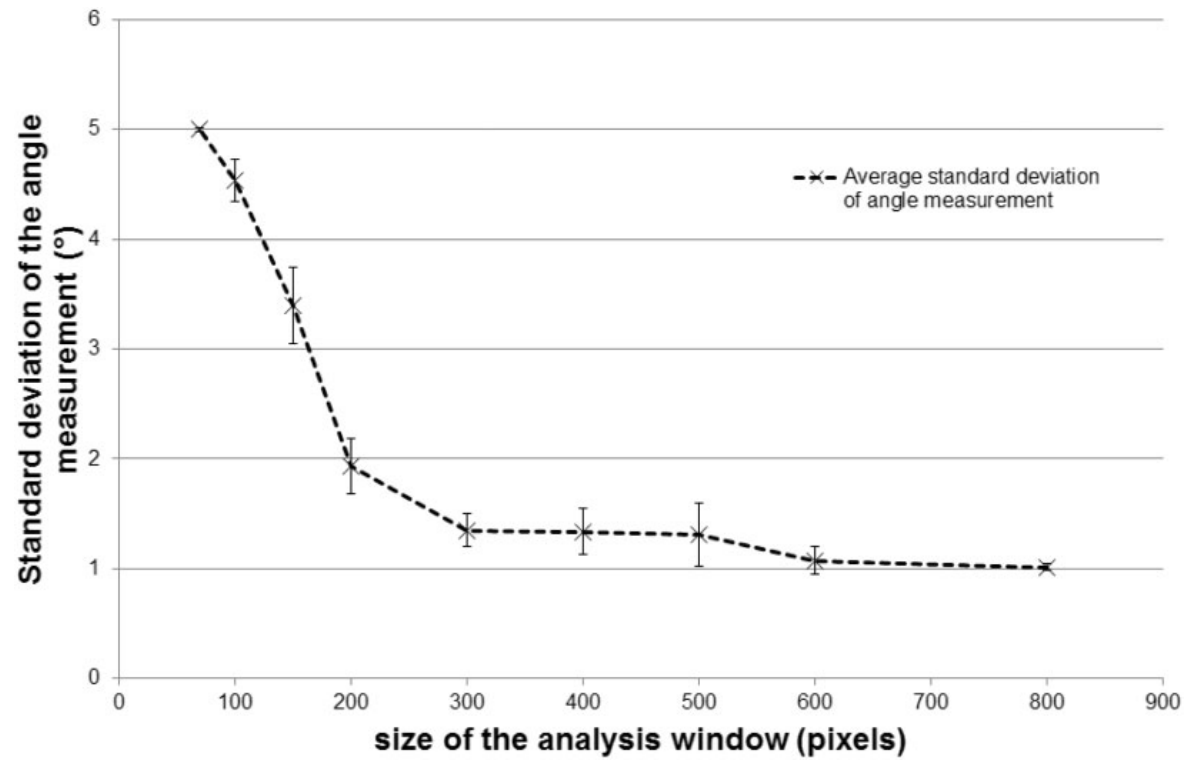

Figure 9. Evolution of the effect of the window size used on the optical fibre orientation measurement (average on all the sub-windows).

as shown in Figure $11 .^{38}$ In this study, eight layers of fabric were used for each measurement in order to minimise the effect of race tracking between fibre bundles at the interface between mould and reinforcement. Using eight layers also ensured that effects of local reinforcement variability on the permeability, which were particularly prominent in the flax samples, were minimised. For increased reliability in the results, three repeats were performed for each measurement configuration. The permeability tensor and its orientations were then computed using Darcy's law by fitting an ellipse to the flow front. ${ }^{40}$

$$
\begin{gathered}
K_{1}=\left\{x_{f}^{2}\left[2 \ln \left(\frac{x_{f}}{x_{0}}\right)-1\right]+x_{0}^{2}\right\} \frac{1}{t} \frac{\mu \varepsilon}{4 \Delta P} \\
K_{2}=\left\{y_{f}^{2}\left[2 \ln \left(\frac{y_{f}}{y_{0}}\right)-1\right]+y_{0}^{2}\right\} \frac{1}{t} \frac{\mu \varepsilon}{4 \Delta P}
\end{gathered}
$$

where $x_{f}$ and $y_{f}$ are the coordinates of the flow front in the ellipse-axis referential system and $x_{0}$ and $y_{0}$ the dimension of the inlet hole. The porosity is defined by $\varepsilon, t$ is the injection time and $\Delta P$ is the pressure difference between the injection point and the flow front.

As the resin cure phase of resin transfer molding (RTM) was not relevant in these tests, a Newtonian mineral oil (Mobil DTE series mineral oil), with a viscosity of $0.14 \mathrm{~Pa} \cdot \mathrm{s}$ at $20^{\circ} \mathrm{C}$, was used as the test fluid in place of a thermoset resin. The injection pressure was set to 1.5 bar. Due to the hydrophilic nature of the flax fibre, it was important to use a non-polar test fluid to avoid swelling and absorption of the fluid into the fibre. ${ }^{41}$ The polynomial viscosity model of the oil used was determined using a Parr Physica UDS200 rheometer to account for daily temperature changes the fluid temperature was recorded both in the inlet pot and at the mould surface using thermocouples.

\section{Transverse permeability measurement}

The steady-state and saturated through thickness permeability setup used, presented in Figure 12, was also installed on the Instron 1186 universal testing machine, enabling accurate control of cavity thickness as well as the measurement of the compaction forces applied. The fluid was injected through the thickness direction of the reinforcement material using an applied pressure drop, and the through thickness permeability $\left(K_{z z}\right)$ was computed from the measured flow rate using Darcy's law

$$
K_{z z}=\frac{Q \cdot h \cdot \mu}{A \cdot \Delta P}
$$

where $Q$ is the volumetric flow rate through the sample, $h$ the imposed cavity thickness, $\mu$ the fluid viscosity, $A$ the area of imposed flow and $\Delta P$ the applied pressure differential.

Similar to the in-plane permeability experiments, eight layers of fabric were used for the transverse permeability measurements in order to minimise the effect of the fabric variability on the permeability. Three repeats were performed for each measurement configuration. The injection pressure was set to 1.5 bar. Transient measurements were performed in further studies but require more sophisticated setups relying on flow detection. ${ }^{39,42}$ Each stack of reinforcements 


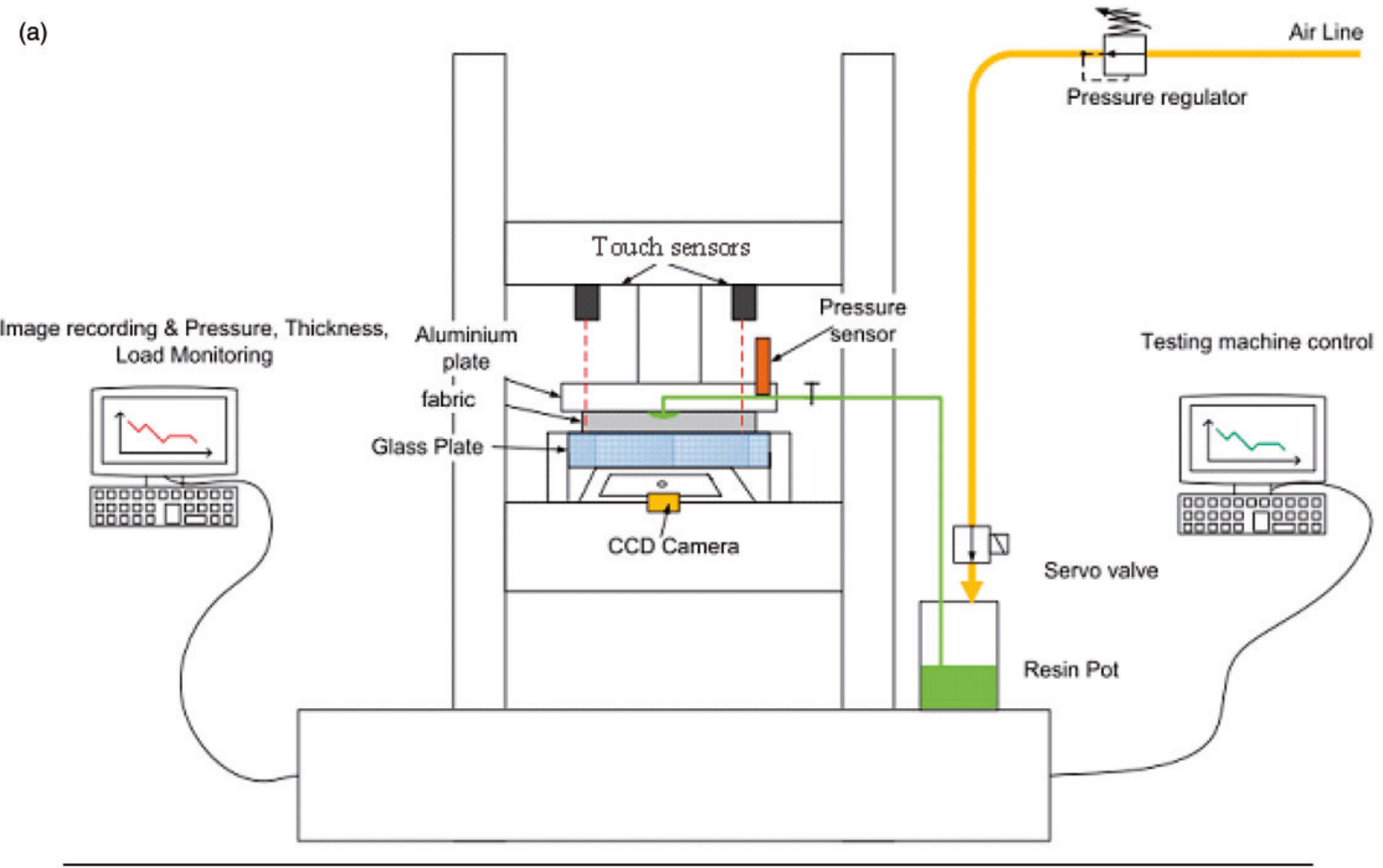

(b)

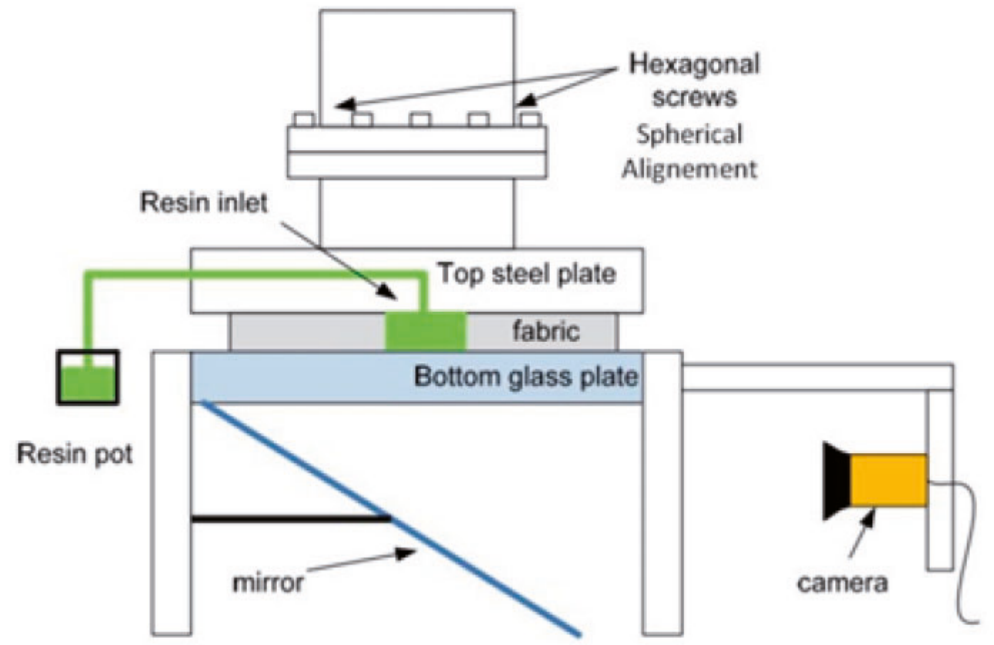

Figure 10. In-plane permeability setup ${ }^{39}$ : (a) overall presentation; (b) zoom on the image acquisition and injection device.

tested was placed between two moulds halves with a specified cavity thickness.

\section{Results and discussion}

The permeability behaviour of the three different materials tested is presented, showing the influence of preform material on the permeability characteristics observed. These comparisons are made on nondeformed preforms (where no shear was applied). Later, the effect of fabric shear on the permeability behaviour is presented and discussed. Figure 13 presents a schematic description of an elliptic flow front on a fabric which was how the permeability here is reported. The components of the in-plane permeability tensor are defined as the principal directions of the ellipse observed at the flow front. Often, these principal directions are different from the warp and weft directions (represented as a grid in Figure 13), and this is distinguished by an angle $\theta$, which is the angle between the weft direction and the direction along the largest principal component of the in-plane permeability tensor. It is important to note that each data point in Figure 14 represents three measurements. 


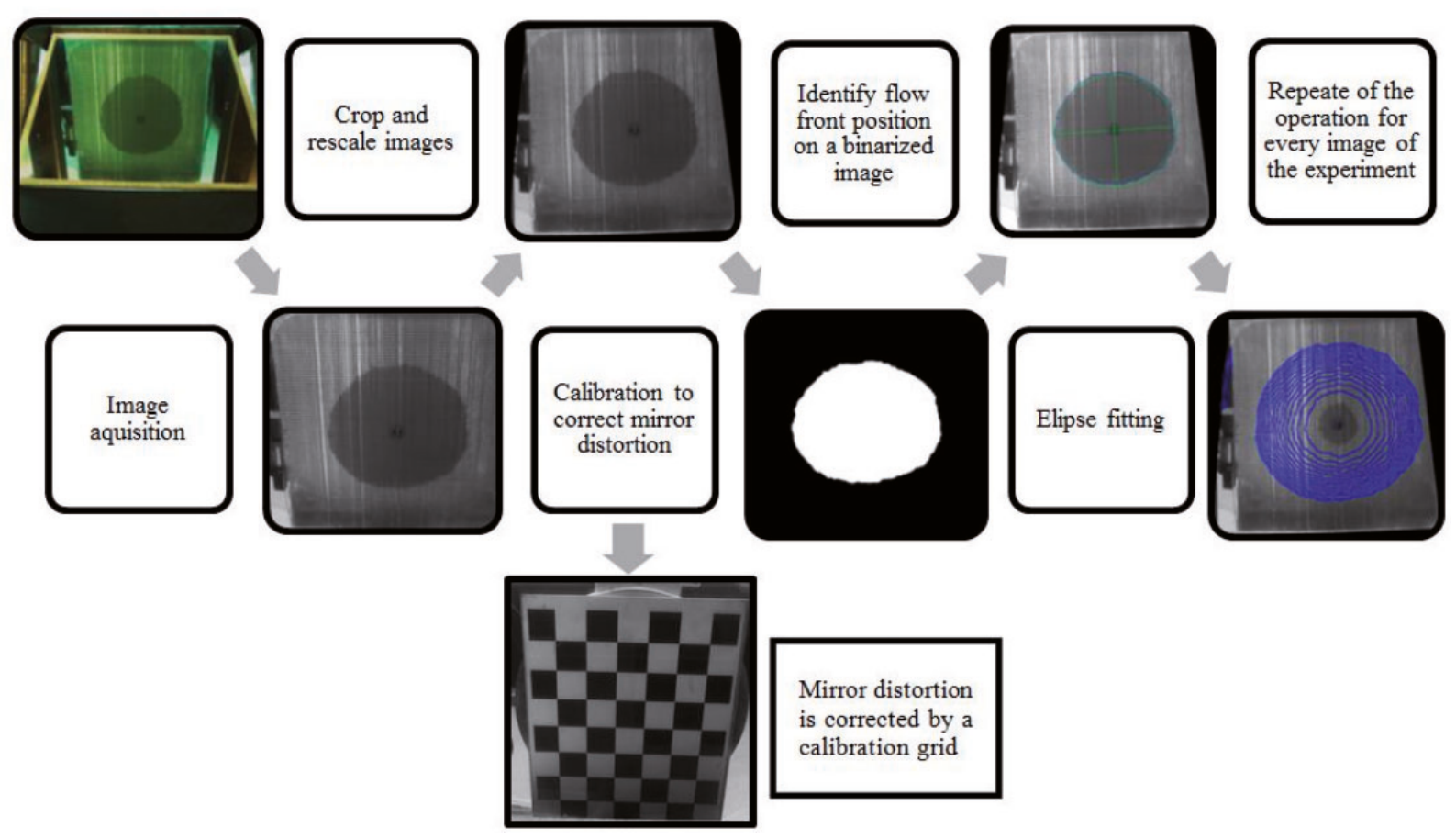

Figure II. Flow front recognition procedure.

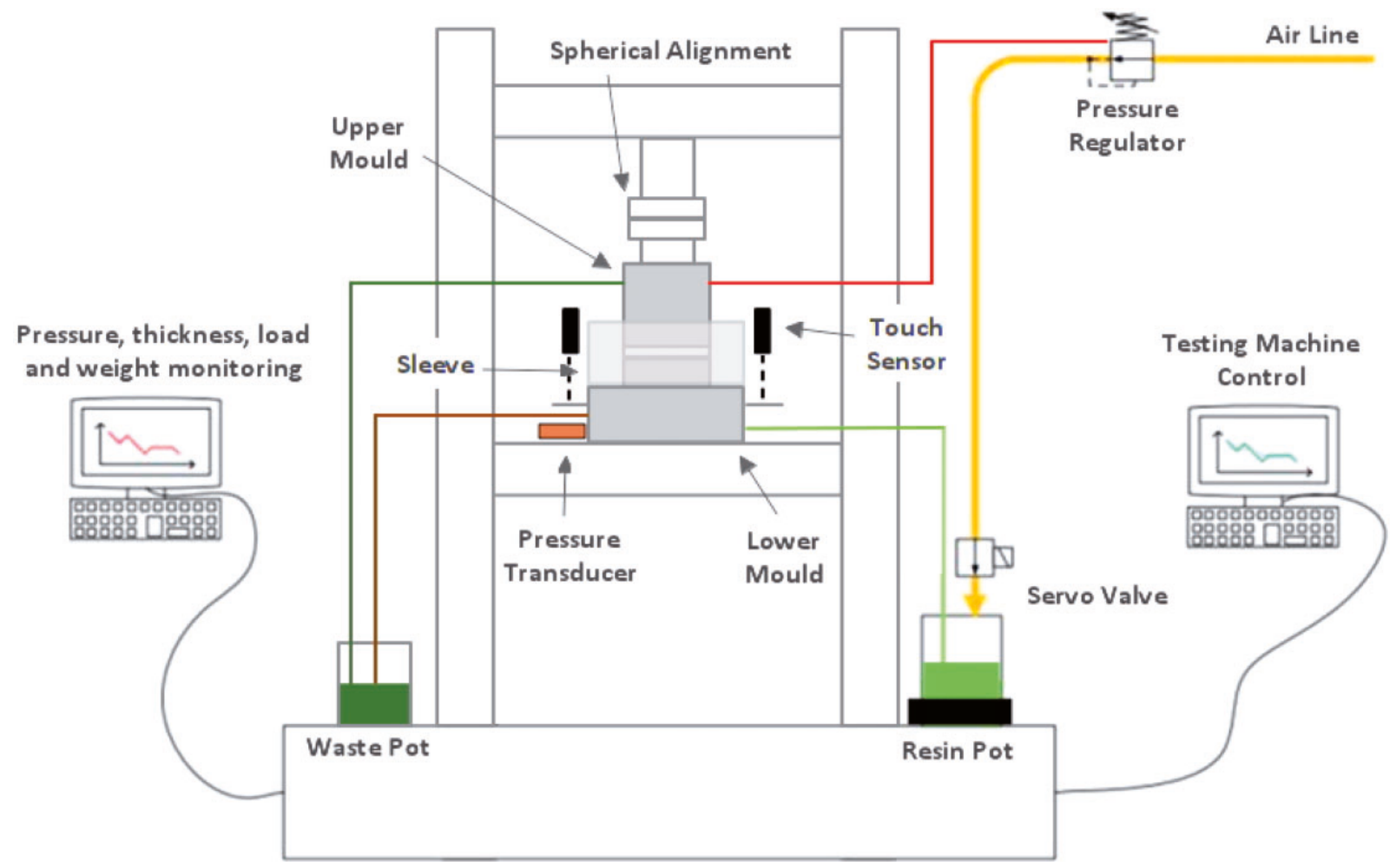

Figure 12. Transverse saturated and steady-state permeability setup. 
The error bars are drawn on every data point, even though in some instances, they are not large enough to see.

\section{Transverse permeability: Comparison between flax and glass reinforcements}

Saturated transverse permeability of the non-sheared woven fabrics was characterised using the setup

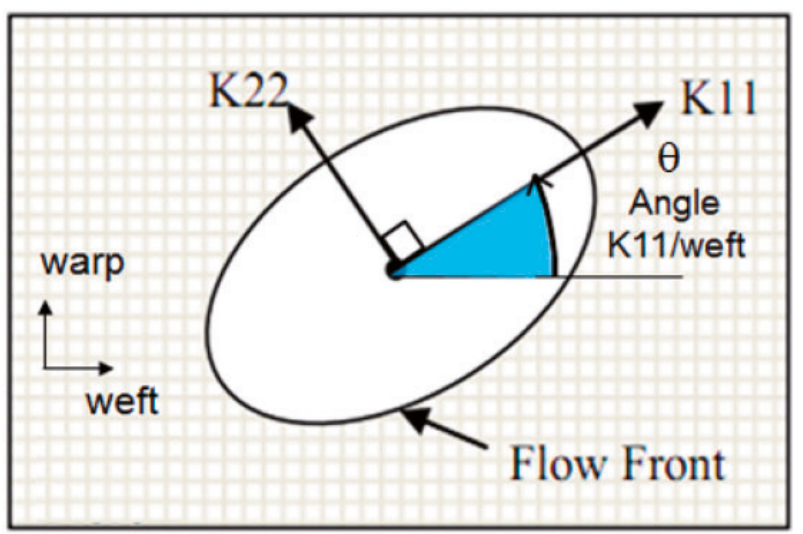

Figure 13. Convention used to define permeability results. described in Transverse Permeability Measurement section (Figure 14). The permeability of the glass reinforcement was found to be significantly different from the permeability of the flax reinforcement of equivalent architecture. In contrast to this, the two flax reinforcements tested displayed similar permeability behaviours even though they had different tow architecture. This shows that the nature of the fibre potentially has a larger effect on permeability when compared to its weaving architecture. In order to confirm this, the same measurements were repeated using the in-plane permeability setup.

\section{In-plane permeability: Comparison between flax and glass reinforcements}

Figure 15 shows that the two flax reinforcements tested displayed similar transient in-plane permeability behaviours. This permeability behaviour is moderately different from the glass fibre reinforcement behaviour. Like in the saturated and steady-state transverse permeability tests, it appears that the permeability behaviour is more dependent on the constituent reinforcing material rather than on its architecture (in this case, varying tow sizes). This could be due to the morphology of the fibres

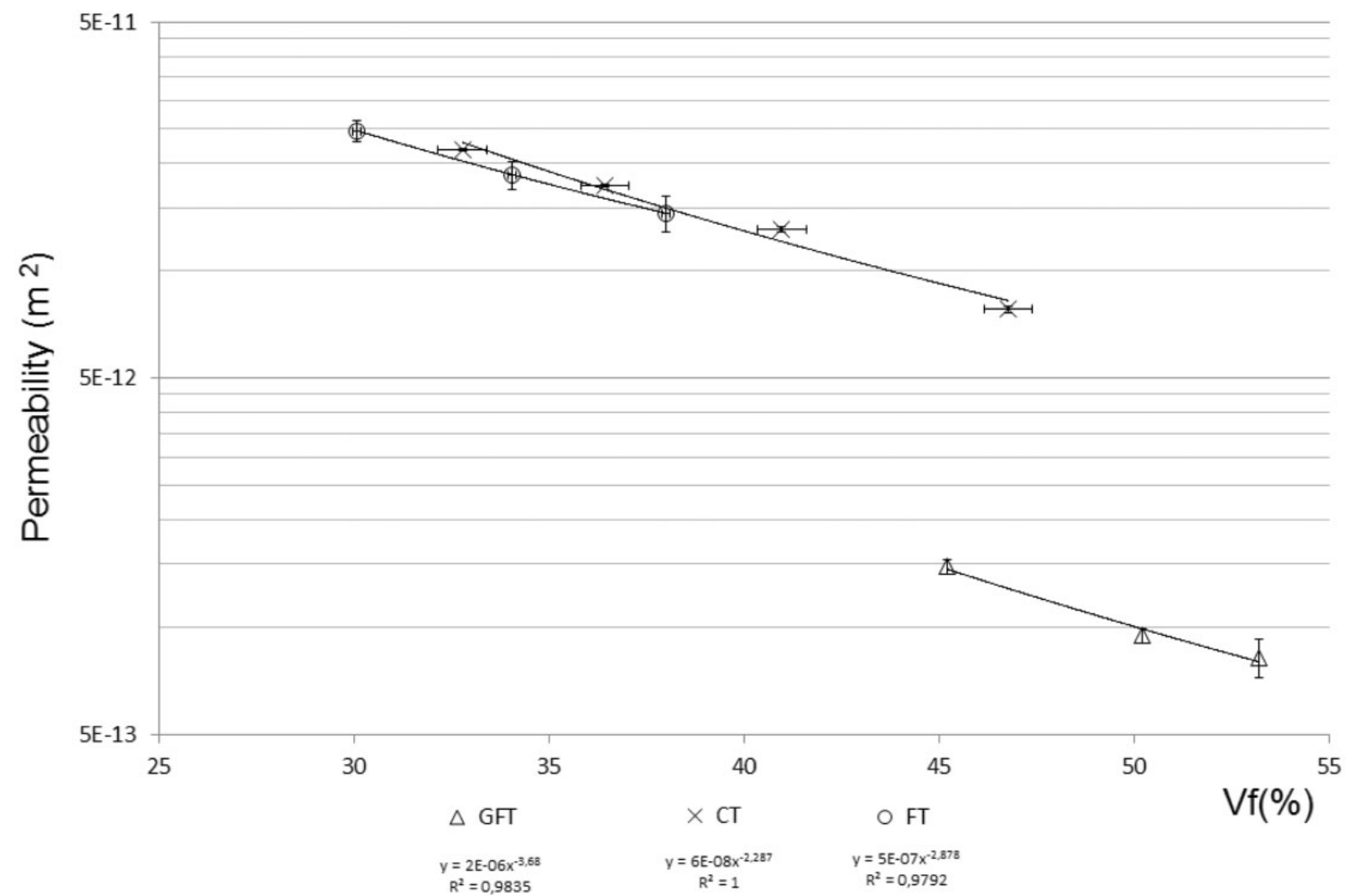

Figure 14. Saturated transverse permeability of the reinforcements. GFT: glass fine twill; FT: flax fine twill; CT: flax coarse twill. 


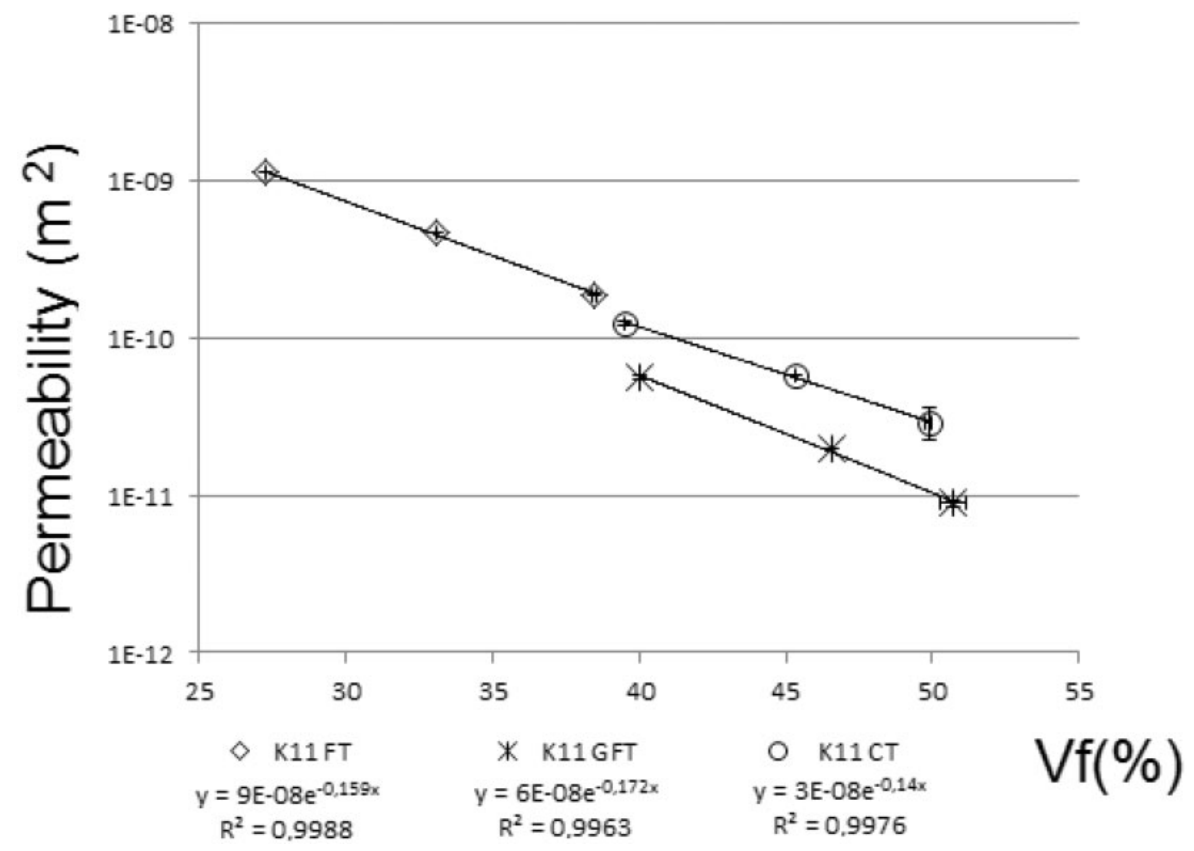

Figure I5. KII (see Figure 14) for the three different unsheared reinforcements: flax fine twill (FT), flax coarse twill (CT) and glass fine twill (GFT).

or the density of the tows. Optical characterisations are in progress to study this particular effect. Even if the Kozeny-Carman law is considered, the size of the fibre cannot explain on its own the amount of differences on measured permeability. The effect of the tow size appears to be irrelevant (Figures 14 and 15).

The difference between flax and glass reinforcements permeability appears higher in the through the thickness direction. At equivalent $V_{f}$, the flax fabric's transverse permeability is about one order of magnitude higher than for the glass fabric. The in-plane permeability of the flax fabric is only doubled compared to the glass one. The higher through thickness permeability of the flax fabric could partly be explained by the shape of the fibre bundles; ${ }^{43,44}$ the glass fabric has lenticular-shaped fibre bundles which are able to better overlap and block macro channels through the thickness, compared to the cylindrical shape of the flax fibre bundles (Figures 2 and 3). In the in-plane direction, the saturation and capillary effects might be more prominent in the glass fabrics since surface energy of glass fibres is lower that of the flax fibres ${ }^{45}$ and compensate partly the larger macropores of the flax reinforcement.

\section{Effect of shearing}

In order to characterise the behaviour of the woven fabric on complex surfaces, such as double curvatures, an in-plane shear deformation was applied. This inplane shear resulted in a change of the reinforcement areal density. It is thus important to consider this during the experiments in order to properly account for the change in fibre volume fraction.

The overall fibre volume fraction of a sheared woven fabric can be calculated using the following equation (9) established from basic geometrical considerations:

$$
\mathrm{V}_{f_{\text {shear }}}=\frac{\mathrm{m}}{\rho f \mathrm{~h} \mathrm{~A} \cos \left(\alpha_{T}\right)}=\frac{V_{f_{\text {noshear }}}}{\cos \left(\alpha_{\tau}\right)}
$$

where $m$ is the sample mass, $\rho_{f}$ the specific mass of the fibre, $h$ the cavity thickness, $A$ the area of the fabric before shearing, $\alpha_{T}$ the overall shear angle and $V_{f_{n s s h e a r}}$ the fibre volume fraction achieved at the same thickness if the fabric had not been sheared.

In order to characterise the effect of the applied shear angle as well as the influence of varying fibre volume fractions, four different nominal shear angles and three different fibre volume fractions were tested. For example, for the coarse twill, the selected shear angles were $0^{\circ}, 10^{\circ}, 15^{\circ}$ and $20^{\circ}$ and the nominal fibre volume fractions selected after compaction tests were $40 \%, 47 \%$ and $54 \%$. The shear angles and fibre volume fractions were chosen after compaction test so as to ensure that these parameters will be realistic for LCM process applications. Due to compliance errors, the nominally chosen values were not achieved, and the actual physical parameters have thus been measured for each experiment. The fibre volume fractions were corrected with the in-situ measurement of the mould cavity (Figure 9) using touch sensors. 


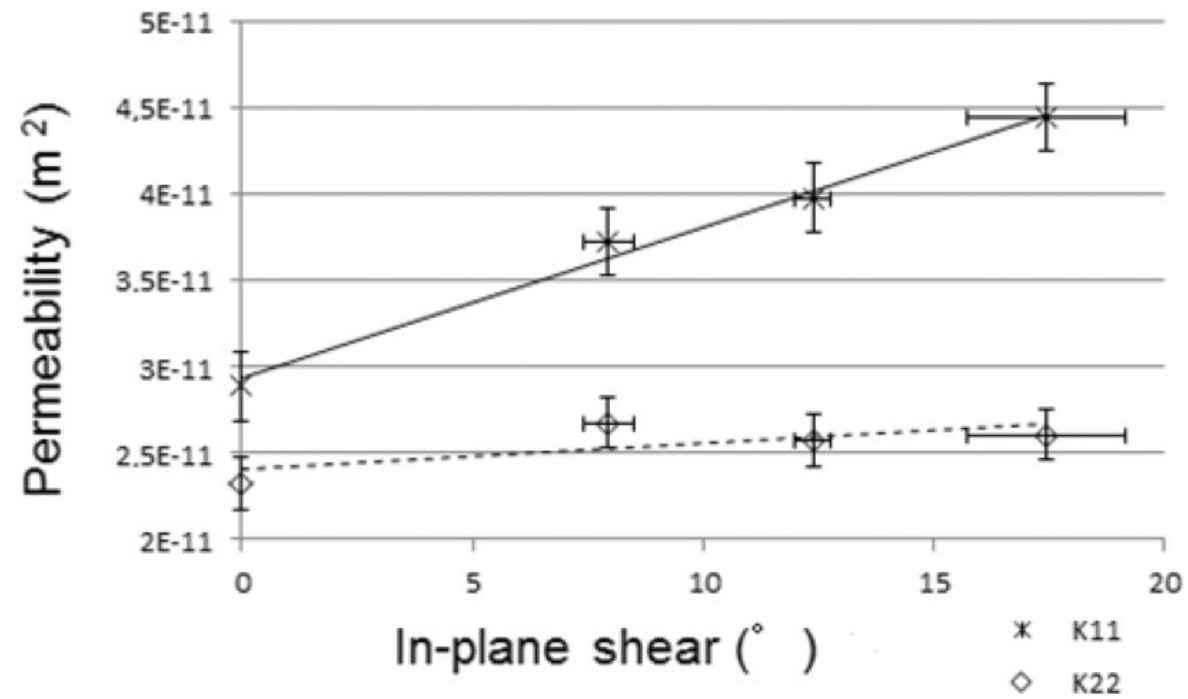

Figure 16. $\mathrm{KII}$ and $\mathrm{K} 22$ at constant $V_{f}\left(V_{f}=54 \%\right)$ at different measured in-plane shear.

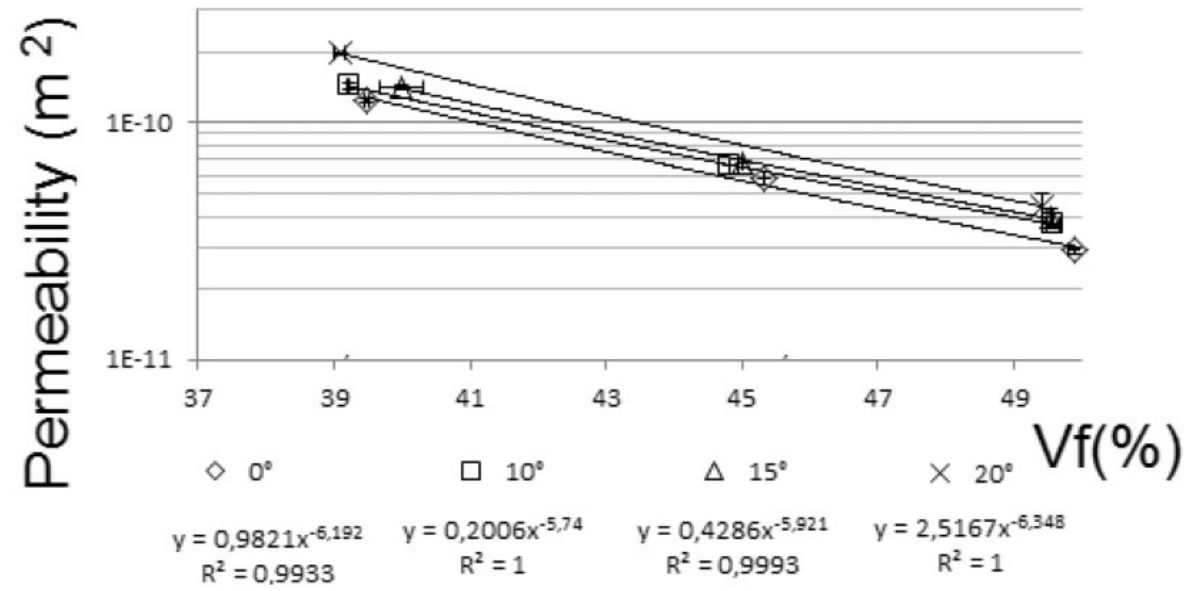

Figure 17. Measurements of $\mathrm{KII}$ at a range of fibre volume fraction for several nominal shear angles.

Figure 16 shows the influence that the applied shear at constant fibre volume fractions $\left(V_{f}=54 \%\right)$ has on the K11 and K22 permeability values on the coarse twill material. As shown in this figure, K11 is significantly affected by shearing, whereas the changes in K22 are not significant. Figures 17 and 18 show that these effects of applied shear appear to be independent of the fibre volume fraction tested. The trend lines for the different shear angles are almost parallel.

It is important to note that the K11 permeability component increases with the shear applied when observed at constant fibre volume fraction. This can be explained by the reorientation of the weft and warp direction; the angle between the weaving direction decreases below $90^{\circ}$ and the channel between fibre bundles tend to align towards K11 direction. It should, however, be noted that if the permeability values are compared at constant thickness, the effect of increased $V_{f}$ would result in an apparent slight decrease of $\mathrm{K} 11$ and a steep drop in K22 with increasing shear.

The ratio between the $\mathrm{K} 11$ and $\mathrm{K} 22$ components, referred to as the in-plane anisotropy ratio, depends on the shear applied to the fabric. Figures 18 and 19 show that, as was seen in Figure 16, the in-plane anisotropy increases with increasing shear angle. The angle between the weft direction and the principal direction of the permeability tensor K11 (angle $\theta$; Figure 13) is also significantly influenced by the shear angle applied. An example of the effect of the shear on the angle $\theta$ (Figure 13) for the coarse twill is presented in Figures 20 and 21. This highlights the importance of accurately characterising the influence that these 


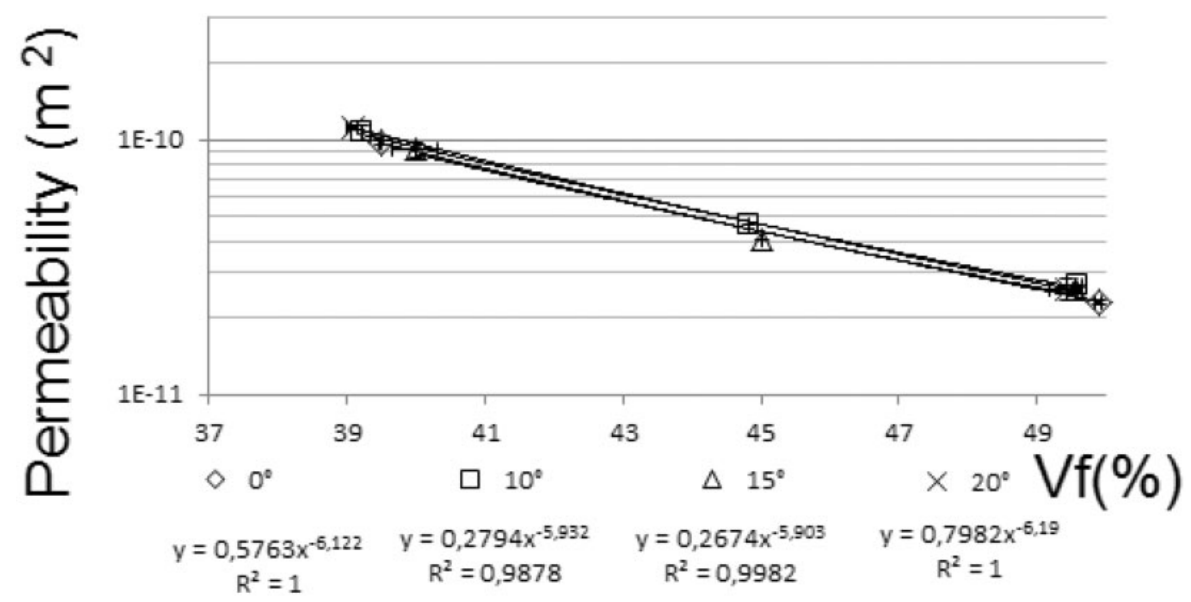

Figure 18. Measurements of K22 depending on the fibre volume fraction for several nominal shear angles.

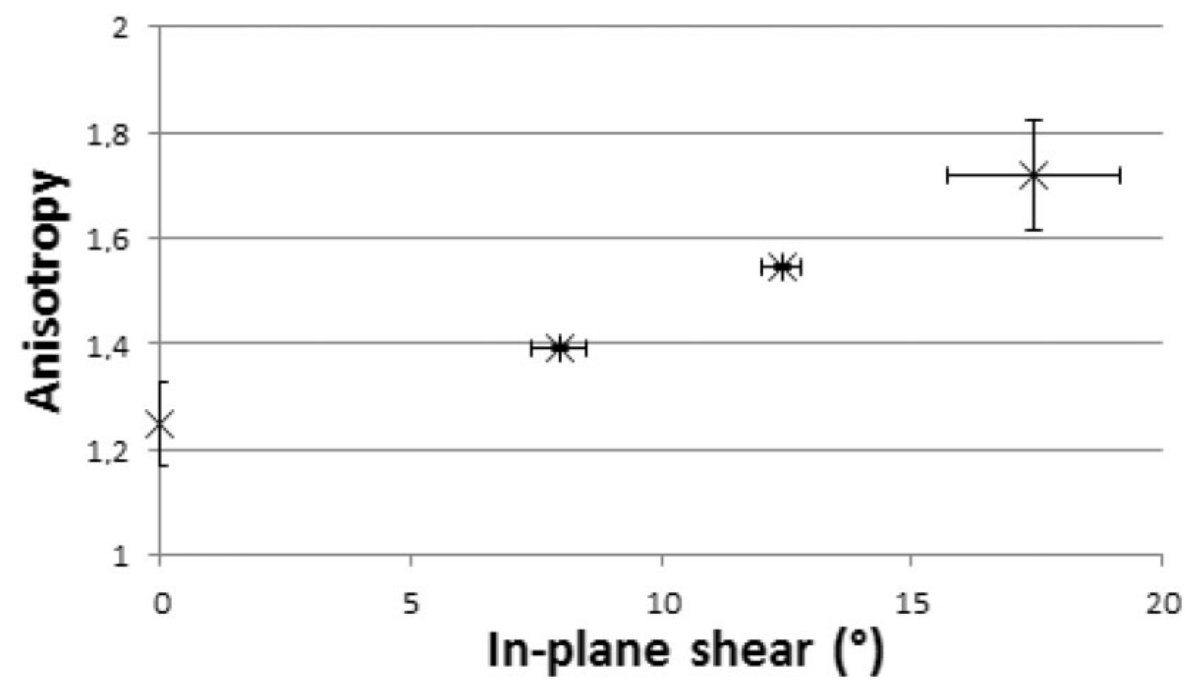

Figure 19. In-plane anisotropy ratio depending on the nominal shear at constant fibre volume fraction on the coarse twill $\left(V_{f}=54 \%\right)$.

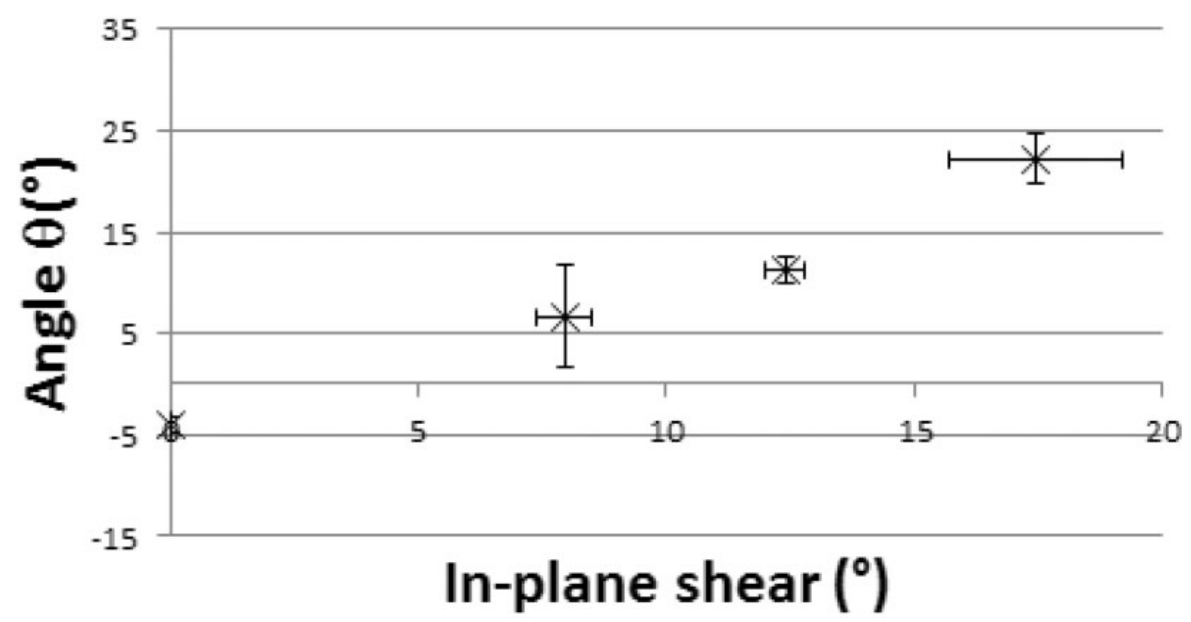

Figure 20. Angle $\theta$ depending on the nominal shear angle at constant fibre volume fraction $\left(V_{f}=54 \%\right)$ on the coarse twill. 

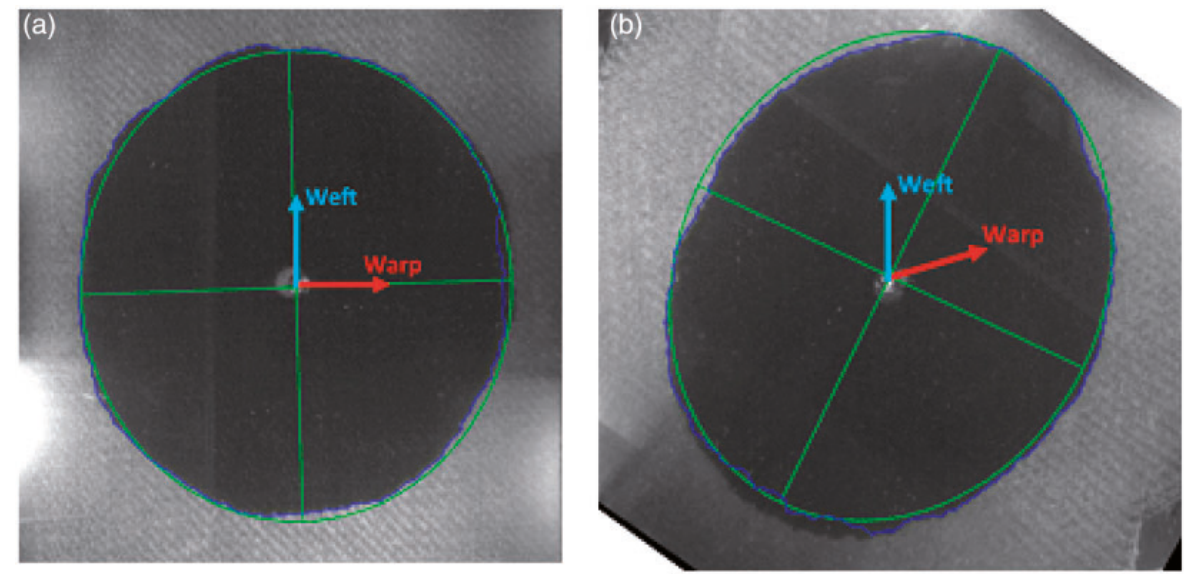

Figure $2 \mathrm{I}$. Ellipse of wet fabric during in plane permeability characterisation at constant fibre volume fraction $\left(V_{f}=54 \%\right)$ : (a) non-shear fabric; (b) nominal shear angle $20^{\circ}$.

parameters have on the material permeability behaviour in order to increase the accuracy of the LCM process models.

\section{Conclusion}

In this paper, an automated optical technique for measuring local fibre orientation and shear on a woven fabric was presented. This technique, which does not need the use of any speckle pattern or other marking of the fibre, was coupled with permeability measurement methods to assess the effects that draping and preforming the textiles have on the manufacturing of woven reinforcement through LCM processes. The effects of shear on the $V_{f}$ and permeability were decoupled to improve the understanding of each effect and improve the measurement accuracy.

Despite the differences between the fine and coarse flax twill weave fabrics, their behaviour in term of permeability relative to the fibre volume fraction is similar. The permeability of the glass fabric, however, is significantly lower. It, therefore, appears that the nature of the fibrous material and geometry of the fibre bundle has a higher influence than the tow size for similar weaving. The combined effect of the surface energy in unsaturated measurements and the morphological effect of tows architectures on both types of measurements have to be discriminated by the use of a permeability estimation model. Those aspects will be taken into account in further studies.

While it is well studied that in-plane shear affects the permeability values and anisotropy behaviour of a fabric, it was demonstrated here that it also affects the orientation of the permeability tensor relative to the fabric orientation (weft and warp).

With the refinement of the LCM process simulation capabilities, ${ }^{24-26,46-50}$ it has become important to be able to provide more accurate and detailed material data to the model. This study has shown the effect of actual local shear, not the theoretical one, on the permeability behaviour of the materials. This will allow the characterisation of semi-empirical models of permeability as a function of permeability and shear, as well as validation of numerical models for permeability prediction currently under development. While there is a drive to try and predict the compaction and permeability behaviour of reinforcement materials through simulation, the large number of parameters and the variability generated through the weaving process does make it difficult and costly to rely solely on prediction to obtain material data, and semi-empirical models based on experimental material characterisation provide economic benefits.

\section{Funding}

This research received no specific grant from any funding agency in the public, commercial, or not-for-profit sectors.

\section{Conflict of interest}

None declared.

\section{References}

1. Mohammed U, Lekakou C and Bader MG. Experimental studies and analysis of the draping of woven fabrics. Compos Part A 2000; 31: 1409-1420.

2. Ouagne P, Soulat D, Moothoo J, et al. Complex shape forming of a flax woven fabric; analysis of the tow buckling and misalignment defect. Compos Part A 2013; 51: $1-10$.

3. Sharma SB, Sutcliffe MPF and Chang SH. Characterisation of material properties for draping of dry woven composite material. Compos Part A 2003; 34: $1167-1175$. 
4. Wang J, Paton R and Page JR. The draping of woven fabric preforms and prepregs for production of polymer composite components. Compos Part A 1999; 30: 757-765.

5. Waris M, Liotier PJ and Drapier S. Effect of the mold on the residual strain field monitored with optical fibers sensors in resin transfer molding processes. J Compos Mater 2013; 48: 2589-2601.

6. Liotier PJ, Vautrin A and Henrat P. Microcracking of composites reinforced by multiply stitched preform subjected to cyclic hygrothermal loadings. Compos Part $A$ 2011; 42: 425-437.

7. Liotier PJ, Vautrin A and Delisée C. 3D morphological characterization and microcracks detection in composites reinforced by multiaxial multiply stitched preform. Compos Part A 2010; 41: 653-662.

8. Wisnom MR and Chang F-K. Modelling of splitting and delamination in notched cross-ply laminates. Compos Sci Technol 2000; 60: 2849-2856.

9. Heardman E, Lekakou C and Bader MG. In-plane permeability of sheared fabrics. Compos Part A 2001; 32: 933-940.

10. Verleye B, Croce R, Griebel M, et al. Permeability of textile reinforcements: simulation, influence of shear and validation. Compos Sci Technol 2008; 68: 2804-2810.

11. Louis $M$ and Huber $U$. Investigation of shearing effects on the permeability of woven fabrics and implementation into LCM simulation. Compos Sci Technol 2003; 63: 2081-2088

12. Hou Y, Comas-Cardona S, Binetruy C, et al. Gas transport in fibrous media: application to in-plane permeability measurement using transient flow. J Compos Mater 2013; 47: 2237-2247.

13. Arbter R, Beraud JM, Binetruy C, et al. Experimental determination of the permeability of textiles: a benchmark exercise. Compos Part A 2011; 42: 1157-1168.

14. Šimáček $P$ and Advani SG. Permeability model for a woven fabric. Polym Compos 1996; 17: 887-899.

15. Parnas RS, Howard JG, Luce TL, et al. Permeability characterization. Part 1: a proposed standard reference fabric for permeability. Polym Compos 1995; 16: 429-445.

16. Loix F, Badel P, Orgéas L, et al. Woven fabric permeability: from textile deformation to fluid flow meso-scale simulations. Compos Sci Technol 2008; 68: 1624-1630.

17. Bickerton S, Simacek P, Guglielmi SE, et al. Investigation of draping and its effects on the mold filling process during manufacturing of a compound curved composite part. Compos Part A 1997; 28: 801-816.

18. Sharma SB and Sutcliffe MPF. A simplified finite element model for draping of woven material. Compos Part $A$ 2004; 35: 637-643.

19. Hamila N, Boisse $P$ and Chatel S. Semi-discrete shell finite elements for textile composite forming simulation. Int J Mater Form 2009; 2: 169-172.

20. Gereke T, Döbrich O, Hübner H, et al. Experimental and computational composite textile reinforcement forming: a review. Compos Part A 2013; 46: 1-10.

21. Abdiwi F, Harrison P, Koyama I, et al. Characterising and modelling variability of tow orientation in engineering fabrics and textile composites. Compos Sci Technol 2012; 72: 1034-1041.

22. Lai C-L and Young W-B. Model resin permeation of fiber reinforcements after shear deformation. Polym Compos 1997; 18: 642-648.

23. Walther J, Simacek P and Advani SG. The effect of fabric and fiber tow shear on dual scale flow and fiber bundle saturation during liquid molding of textile composites. Int J Mater Form 2012; 5: 83-97.

24. Demaria C, Ruiz E and Trochu F. In-plane anisotropic permeability characterization of deformed woven fabrics by unidirectional injection. Part I: experimental results. Polym Compos 2007; 28: 797-811.

25. Demaria C, Ruiz E and Trochu F. In-plane anisotropic permeability characterization of deformed woven fabrics by unidirectional injection. Part II: prediction model and numerical simulations. Polym Compos 2007; 28: 812-827.

26. Dungan FD, Senoguz MT, Sastry AM, et al. On the use of Darcy permeability in sheared fabrics. J Reinforc Plast Compos 1999; 18: 472-484.

27. Boisse P, Hamila N, Vidal-Sallé E, et al. Simulation of wrinkling during textile composite reinforcement forming influence of tensile, in-plane shear and bending stiffnesses. Compos Sci Technol 2011; 71: 683-692.

28. Bel S, Hamila N, Boisse P, et al. Finite element model for NCF composite reinforcement preforming: importance of inter-ply sliding. Compos Part A 2012; 43: 2269-2277.

29. Skordos AA, Aceves CM and Sutcliffe MPF. A simplified rate dependent model of forming and wrinkling of pre-impregnated woven composites. Compos Part A 2007; 38: $1318-1330$

30. Prodromou AG and Chen J. On the relationship between shear angle and wrinkling of textile composite preforms. Compos Part A 1997; 28: 491-503.

31. Cao J, Akkerman R, Boissec P, et al. Characterization of mechanical behavior of woven fabrics: experimental methods and benchmark results. Compos A 2008; 39: 1037-1053.

32. GerekeT, Döbrich O, Hübner M, et al. Experimental and computational composite textile reinforcement forming: a review. Compos A 2013; 46: 1-10.

33. Willems A, Lomov SV, Verpoest I, et al. Optical strain fields in shear and tensile testing of textile reinforcements. Compos Sci Technol 2008; 68: 807-819.

34. Gonzalez RC, Woods RE and Eddins SL. Digital image processing using MATLAB, 2nd ed. Tennessee: Gatesmark Publishing, 2009.

35. Cardamone JM, Damert WC, Philips JC, et al. Digital image analysis for fabric assessment. Text Res $J$ 2002; 72: 906-916.

36. Ballard D and Brown C. Computer vision. Prentice-Hall, 1982, pp.24-30.

37. Walbran WA, Bickerton S and Kelly PA. Evaluating the shear component of reinforcement compaction stress during liquid composite moulding processes. J Compos Mater 2013; 47: 513-528.

38. Comas-Cardona S, Cosson B, Bickerton S, et al. An optically-based inverse method to measure in-plane permeability fields of fibrous reinforcements. Compos Part $A$ 2014; 57: 41-48. 
39. Drapier S, Monatte J, Elbouazzaoui O, et al. Characterization of transient through-thickness permeabilities of Non Crimp New Concept (NC2) multiaxial fabrics. Compos Part A 2002; 36: 877-892.

40. Shenoi RA, Wilson PA and Weitzenböck JR. Radial flow permeability measurement. Part A: theory. Compos Part A 1999; 30: 1685-1697.

41. Umer R, Bickerton S and Fernyhough A. Characterising wood fibre mats as reinforcements for liquid composite moulding processes. Compos Part A 2007; 38: 434- 448.

42. Ouagne $\mathrm{P}$ and Bréard J. Continuous transverse permeability of fibrous media. Compos Part A 2010; 41: 22-28.

43. Swery E, Meier R, Lomov S, et al. Verification of FlowTex Solver using Ansys CFX; Examining the permeability prediction method on a range of textile architecture models. In: Proceedings of the 16th European conference on composite materials, Seville, Spain, 2014.

44. Swery E, Kelly PA, Walbran WA, et al. Numerical permeability prediction of woven textiles at different compaction levels. In: TexComp 11, Leuven, Belgium, 2014.

45. Pucci M, Liotier PJ and Drapier S. Capillary effects on flax fibers reinforcement: comparison of chemical and morphological effects on the local wetting dynamics. In: Proceedings of the 12th international conference on flow processing in composite materials, Enschede at Twente University, Western Netherland, 14-16 July 2014.

46. Aranda S, Berg DC, Dickert M, et al. Influence of shear on the permeability tensor and compaction behaviour of a non-crimp fabric. Compos Part B Eng 2014; 65: $158-163$.

47. Govignon Q, Bickerton S and Kelly PA. Simulation of the reinforcement compaction and resin flow during the complete resin infusion process. Compos Part A 2010; 41: 45-57.

48. Celle P, Drapier S and Bergheau J-M. Numerical modelling of liquid infusion into fibrous media undergoing compaction. Eur J Mech A/Solids 2008; 27: 647-661.

49. Moulin N, Abouorm L, Bruchon J, et al. Monolithic approach of stokes-Darcy coupling for LCM process modelling. Key Eng Mater 2013; 554: 447-455.

50. Pacquaut $\mathrm{G}$, Bruchon $\mathrm{J}$, Moulin N, et al. Combining a level-set method and a mixed stabilized $\mathrm{P} 1 / \mathrm{P} 1$ formulation for coupling Stokes-Darcy flows. Int $J$ Numerical Methods Fluids 2012; 69: 459-480. 